\title{
A oftalmologia no tribunal: avaliação das sentenças judiciais no âmbito do Tribunal de Justiça do Estado de São Paulo
}

\author{
Ophthalmology in Court: evaluation of sentences according to The Justice \\ Court of Sao Paulo - Brazil
}

\author{
Karen Yamauti'; ${ }^{1}$ Talita Zerbini²
}

DOI: http://dx.doi.org/10.11606/issn.2317-2770.v19i2p78-85

\begin{abstract}
Yamauti K; Zerbini T. A oftalmologia no tribunal: avaliação das sentenças judiciais no âmbito do Tribunal de Justiça do Estado de São Paulo. Saúde, Ética \& Justiça. 2014;19(2):78-85.

RESUMO: A oftalmologia envolve tratamentos clínicos e cirúrgicos com um amplo espectro de patologias, é uma especialidade sujeita a processos judiciais em diversos campos. As ações contra médicos oftalmologistas e entidades médicas vão desde insatisfações com óculos a resultados de procedimentos cirúrgicos complexos. Sendo assim, o objetivo do trabalho foi avaliar os processos referentes a erro médico na área de oftalmologia julgados em segunda instância pelo Tribunal de Justiça do Estado de São Paulo (TJ-SP). Foi realizado levantamento de dados online das sentenças de acórdãos em segunda instância, através de pesquisa das jurisprudências disponíveis no site do Tribunal de Justiça do Estado de São Paulo (TJ-SP) entre 01/01/1997 e 30/09/2014, utilizando os termos "oftalmologista" e "erro médico" no campo disponibilizado para pesquisa. O levantamento resultou em um total de 100 acórdãos, sendo incluídos 55 de interesse para o estudo. Todas as ações apresentavam acusação por erro médico; 91\% envolviam procedimentos cirúrgicos. Em 61,8\% dos acórdãos o autor alegou cegueira e em $23,6 \%$, dano estético. Na maioria dos casos (90,9\%) houve perícia médica, e a decisão do juiz baseou-se no laudo pericial em $86 \%$ das vezes. Em relação à decisão judicial, $81,8 \%$ dos pedidos foram indeferidos em segunda instância, 9,1\% deferidos e 9,1\% obtiveram provimento parcial do pedido. Os dados apresentados mostraram, entre outros achados, o papel fundamental da perícia médica nos processos por erro médico, expondo a sua importância nas decisões judiciais.
\end{abstract}

DESCRITORES: Oftalmologia; Erros médicos, negligência, jurisprudência.

\footnotetext{
1. Médica Oftalmologista do Centro de Referência em Oftalmologia - SP. E-mail: karenyamauti@,hotmail.com

2. Faculdade de Ciências Médicas da Santa Casa, Central de Convênios da Fundação ABC, Instituto Médico Legal de São Paulo. E-mail: tazerbini@yahoo.com.br
} 


\section{INTRODUÇÃO}

$\mathrm{T}$ Temos observado ao longo das últimas décadas um fenômeno de mudança progressiva e dramática no cenário médico-legal em todo o mundo. Segundo dados do Superior Tribunal de Justiça (STJ), a quantidade de processos envolvendo erros médicos que chegaram à Corte aumentou $200 \%$ no período de 2003 a $2008^{1}$. No estado de São Paulo, de acordo com estudo publicado pelo Conselho Regional de Medicina do Estado de São Paulo (CREMESP), no período de 2000 a 2006 o número de médicos denunciados aumentou $75 \%$ e o número de processos em andamento cresceu $120 \%{ }^{2}$.

O distanciamento entre os pacientes e médicos se tornou o cerne de grande parte dos processos judiciais na área médica. Testemunhamos um "esfriamento" da relação médico-paciente, esta que já foi uma das mais importantes relações de confiança, humanidade, envolvimento e responsabilidade e que vem se transformando cada vez mais em relação de consumo, em que os resultados de tratamentos e procedimentos médicos são comparados a produtos e serviços prestados. A indústria judicial do erro médico, a exemplo do que ocorre em outros países, encontra no contexto nacional um terreno fértil para proliferação de processos médico-legais baseados nas mais diversas causas, desde tratamentos clínicos, cirúrgicos e estéticos, a questões comportamentais, como a falta de comunicação, falha na orientação e antipatia ${ }^{3}$.

A oftalmologia, por suas características singulares, e por se tratar de área médica que envolve tratamentos clínicos e cirúrgicos com um amplo espectro de patologias, é uma especialidade sujeita a processos judiciais em diversos campos. As ações contra médicos oftalmologistas, clínicas, hospitais e seguradoras vão desde insatisfação com óculos a resultados de procedimentos cirúrgicos complexos, sendo uma das especialidades que mais sofrem com o posicionamento do paciente como consumidor. Em pesquisa recente que analisou retrospectivamente processos judiciais cíveis em oftalmologia no Estado do Rio de Janeiro ${ }^{4}$, foram observadas diversas questões envolvidas nos litígios, sendo a grande maioria relacionadas com procedimentos cirúrgicos. Além disso, concluiu-se também que um menor contato com o médico antes do procedimento era relacionado com maior probabilidade de processo judicial ${ }^{4}$, o que reforça a importância da relação médico-paciente.

Ao mesmo tempo em que se observa um aumento progressivo no volume de processos contra médicos, não ocorre proporcional interesse da classe médica na temática médico-legal. A Medicina, por envolver um conhecimento amplo e complexo, e muitas vezes subjetivo, impreciso e evolutivo, torna seu julgamento incerto e até impraticável por leigos. Dessa forma, o papel dos próprios médicos é fundamental para fornecer discernimento à Justiça, de modo que esta possa atuar de forma eficiente, pertinente, legítima e, principalmente, justa $^{5}$.

Com o propósito de analisar as sentenças de processos judiciais na área de oftalmologia julgados em segunda instância pelo Tribunal de Justiça do Estado de São Paulo e obter dados para melhor compreender os litígios, desenvolvemos o presente estudo. O trabalho teve como objetivo identificar as principais causas, alegações e argumentos dos autores para o erro médico nas ações processuais pesquisadas, avaliar em quantos casos foi realizada perícia médica e quais os critérios utilizados pelos juízes para a decisão sobre o deferimento ou indeferimento do pedido.

\section{MÉTODO}

Foi realizado levantamento de dados online das sentenças de acórdãos em segunda instância, através de pesquisa das jurisprudências disponíveis no site do Tribunal de Justiça do Estado de São Paulo (TJ-SP) no período de 01/01/1997 e 31/09/2014, utilizando os termos "oftalmologista" e "erro médico" juntos no campo disponibilizado para pesquisa específica.

Com o intuito de dar embasamento científico para a discussão, foi realizado levantamento bibliográfico nas bases de dados Pubmed/Medline e Biblioteca Virtual da Saúde utilizando os descritores Oftalmologia/Ophthalmology; Erro médico/Medicalerros; Jurisprudência, além de ter sido feita consulta de livros conceituados na prática oftalmológica.

Foram incluídos no estudo os acórdãos em segunda instância em que o autor ou reclamante era o paciente e os casos em que o réu era o médico oftalmologista assistente e/ou a instituição médica em que o paciente havia sido atendido (clínica, hospital ou plano de saúde).

\section{RESULTADOS}

O levantamento online das jurisprudências resultou num total de 100 acórdãos. Destes, foram analisados e incluídos 55 acórdãos de interesse para o estudo.

Do total de 55 acórdãos, apenas 8 casos envolviam queixas em caráter de urgência ou emergência e os demais 47 foram ambulatoriais, o que corresponde a $85,5 \%$ do total (Gráfico 1).

Dentre os processos apurados, foram identificadas queixas envolvendo procedimentos cirúrgicos em 91\% dos casos (Gráfico 2). 
Yamauti K; Zerbini T. A oftalmologia no tribunal: avaliação das sentenças judiciais no âmbito do Tribunal de Justiça.

GRÁFICO 1 - Caráter dos atendimentos citados nos acórdãos do TJ-SP

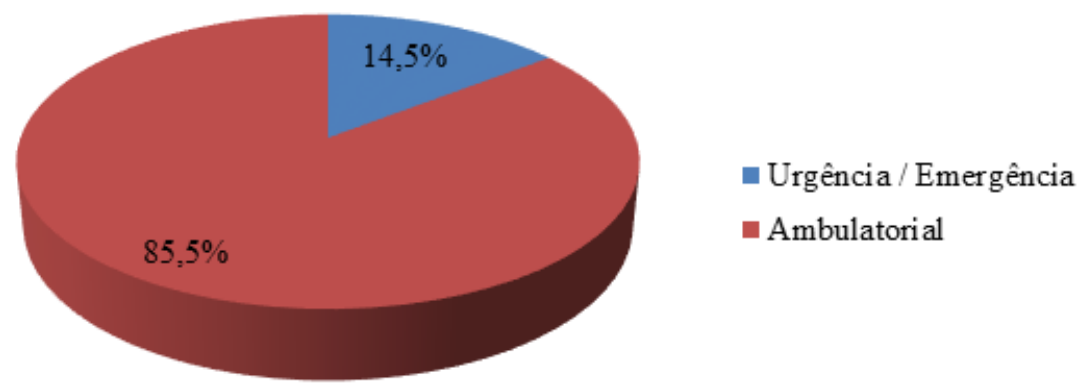

GRÁFICO 2 - Casos Cirúrgicos X Clínicos

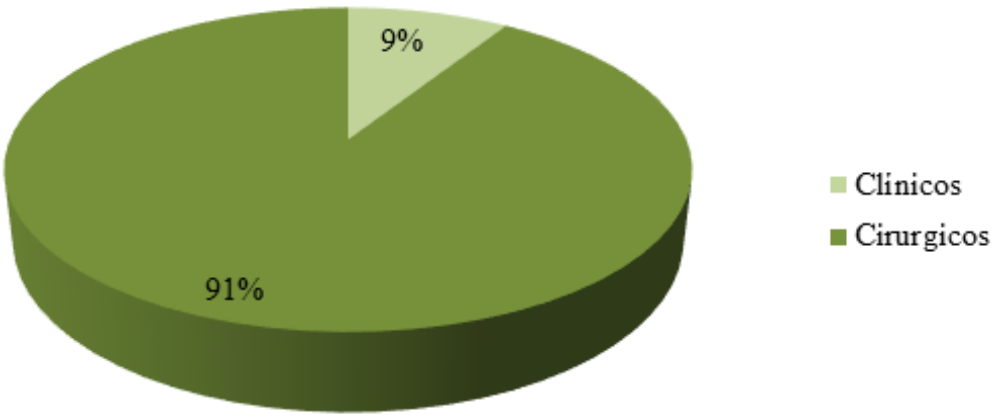

Todas as ações analisadas apresentavam acusação por erro médico, sendo citados negligência, imprudência e imperícia isoladamente ou em conjunto, sobrepondo duas ou mais acusações. Dentro dos 55 litígios, imperícia foi citada 45 vezes, negligência 20 vezes e imprudência 11 vezes.

Em relação à distribuição geográfica, todos os pedidos foram realizados no estado de São Paulo e as comarcas de origem foram divididas em três grupos: São Paulo Capital, Grande São Paulo e interior/litoral. Cinquenta e um por cento dos casos foram registrados na Capital de São Paulo, 18\% na Grande São Paulo e 31\% no interior/litoral do Estado (Gráfico 3).

\section{GRÁFICO 3 - Distribuição geográfica dos acórdãos}

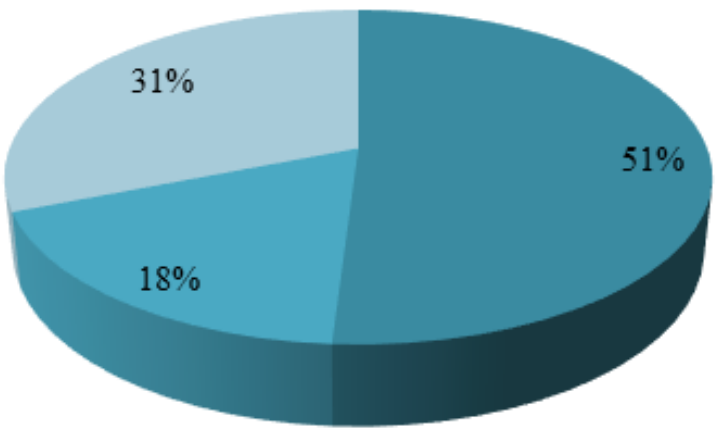


Em relação às queixas estéticas, $23,6 \%$ alegaram sequela de dano estético, sendo somente 1 dos casos diretamente relacionado a resultado de cirurgia estética insatisfatório, os demais não envolviam procedimento estético.
Dos 55 casos avaliados, em $34(61,8 \%)$ o autor alegou cegueira (perda total da visão) como resultado final de erro médico. Entre os restantes, 21,8\% alegaram perda parcial da visão e os demais $16,4 \%$ não se queixaram de perda visual de qualquer natureza (Gráfico 4).

\section{GRÁFICO 4 - Queixas em relação a perda visual}

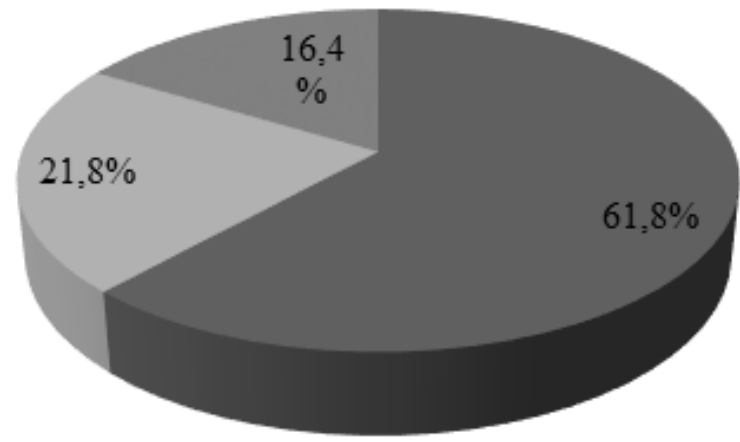

- Perda total (cegueira)

- Perda parcial

- Sem perda de visão

Os litígios foram divididos conforme as diferentes subespecialidades da oftalmologia. Foram observadas as seguintes frequências em ordem decrescente: 36\% cirurgias de catarata; $19 \%$ cirurgias refrativas; $12,7 \%$ córnea e segmento anterior; 7,2\% retina e vítreo; $7,2 \%$ traumas oculares; 5,4\% oculoplástica; 3,6\% uveítes; $3,5 \%$ glaucoma; $1,8 \%$ refração clínica; 1,8 retinopatia da prematuridade e $1,8 \%$ urgências não especificadas (Gráfico 5).

\section{GRÁFICO 5 - Frequência dos processos segundo sub-especialidades da oftalmologia}

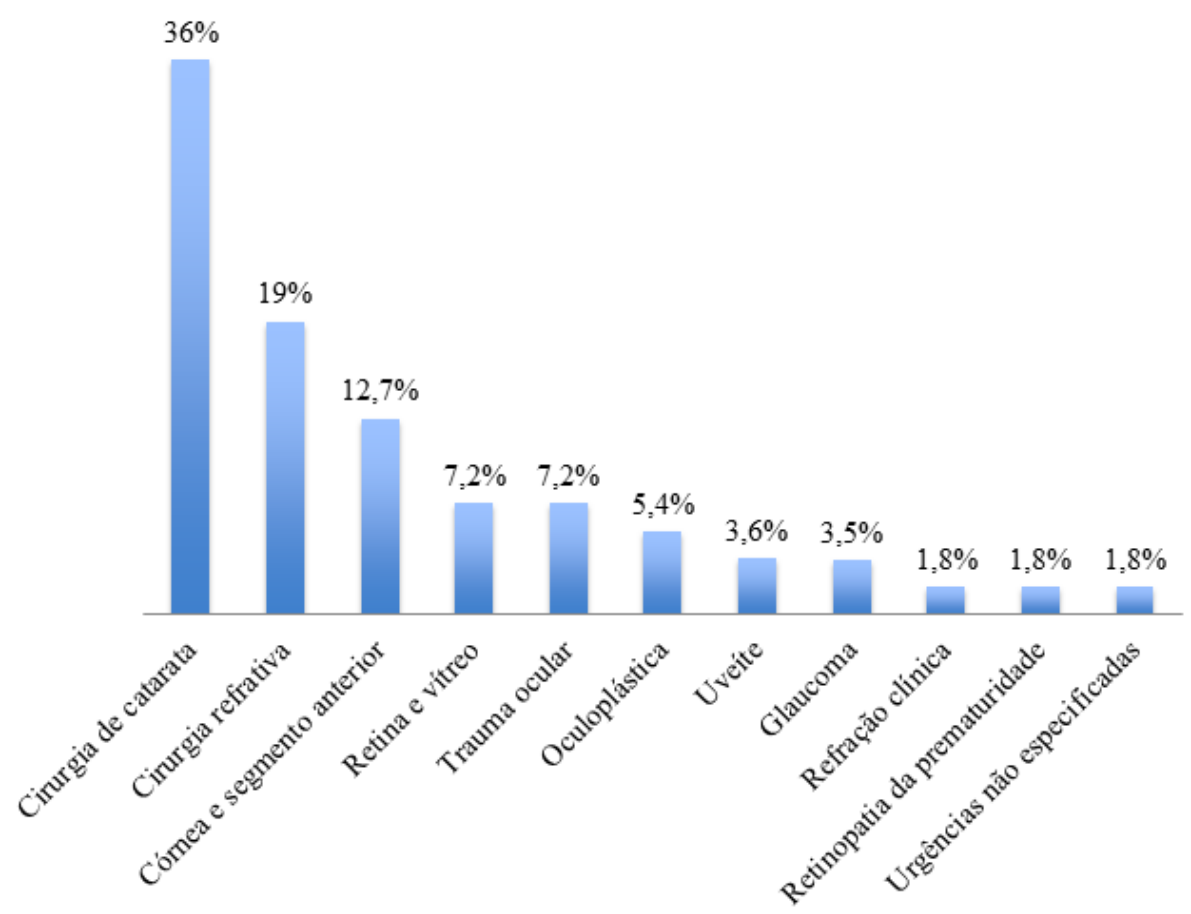


Yamauti K; Zerbini T. A oftalmologia no tribunal: avaliação das sentenças judiciais no âmbito do Tribunal de Justiça.

O pólo de acusação dos acórdãos envolveu o médico oftalmologista e/ou instituição médica (clínica/ hospital/convênio/plano de saúde) onde foi prestada assistência ao autor. A análise mostrou que em 34,5\% dos casos o processo acusou ambos, tanto o médico quanto a instituição de assistência; em $42 \%$ o pólo foi somente a instituição e em $23,5 \%$ dos casos somente o médico foi réu do processo (Gráfico 6).

\section{GRÁFICO 6 - Pólo de acusação dos acórdãos}

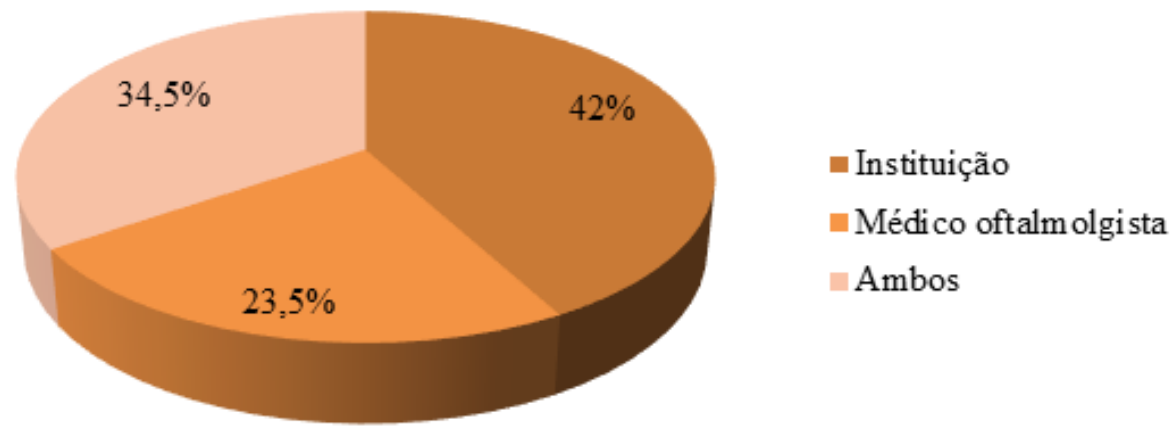

Em relação à decisão judicial, $81,8 \%$ dos pedidos e $9,1 \%$ obtiveram provimento parcial do pedido (Gráfico foram indeferidos em segunda instância, 9,1\% deferidos 7).

\section{GRÁFICO 7 - Decisão judicial em segunda instância}

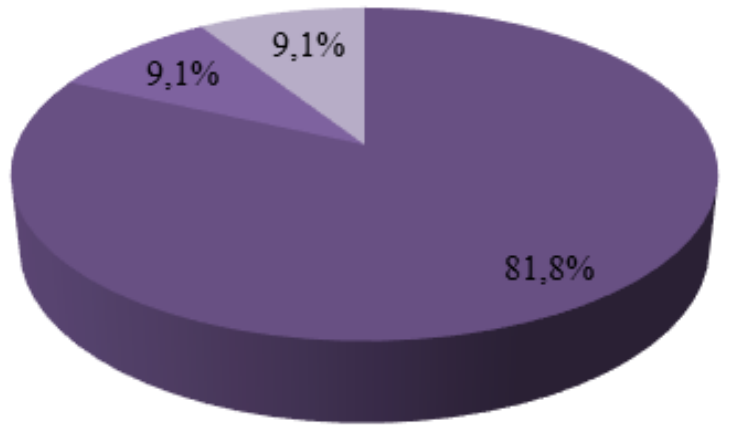

- Indef eridos

- Provimento total

Provimento parcial
$\mathrm{Na}$ maioria dos casos $(90,9 \%)$, o autor foi submetido à perícia médica. Dentre estes casos em que foi realizada a perícia, a decisão do juiz baseou-se no laudo pericial em $86 \%$ dos casos.

Em nenhuma das sentenças avaliadas foi possível ter acesso aos laudos periciais médicos na íntegra, pois nos acórdãos constam somente trechos e conclusões finais dos laudos realizados. Com base nos dados disponíveis foi possível dividir as principais conclusões periciais nos seguintes grupos: 1. "Não foi observado erro em técnica cirúrgica, sendo as complicações dos procedimentos imprevisíveis e inevitáveis, não possuindo nexo causal com a perda visual" $(34,5 \%) ; 2$. "O periciado apresentava patologia ocular de base diversa que causou a perda visual, não sendo estabelecido nexo causal entre a perda visual e o erro médico relatado" (31\%); 3. "Não foi possível estabelecer a presença de erro médico ou nexo causal entre a queixa e o desfecho final" (11\%); 4. "A perícia comprovou a presença de erro médico com nexo causal" $(1,8 \%) ; 5$. "Não houve erro médico, porém foi comprovada irregularidade de atuação do médico junto ao CRM" (1,8\%); 6. "Perícia inconclusiva" $(1,8 \%)$ e em $18,1 \%$ dos casos não havia dados a respeito da conclusão dos laudos periciais (Tabela 1). 
TABELA 1 - Conclusões dos laudos periciais

\begin{tabular}{|c|c|}
\hline Sem erro de técnica, complicações inevitáveis & $34,5 \%$ \\
\hline Patologia de base causou perda visual & $31 \%$ \\
\hline Sem nexo causal entre a queixa e o desfecho final & $11 \%$ \\
\hline Comprovado erro médico & $1,8 \%$ \\
\hline Irregularidade no CRM & $1,8 \%$ \\
\hline Perícia inconclusiva & $1,8 \%$ \\
\hline Sem dados de conclusão & $18,1 \%$ \\
\hline
\end{tabular}

\section{DISCUSSÃO}

Atualmente pouco se sabe sobre dados relacionados a processos médicos na área de oftalmologia no Brasil. Levantamentos realizados abordando a questão são importantes do ponto de vista médico, pois podem auxiliar na identificação, correção e prevenção dos possíveis problemas e pontos fracos nos quais ocorrem falhas na prestação de serviço de saúde. Além disso, a identificação e análise das queixas que levam os pacientes aos tribunais podem colaborar para melhor entender o ponto de vista destes pacientes e seus familiares em relação a suas expectativas, esclarecimentos, orientações e insatisfações.

Por meio do presente estudo, foi possível revelar algumas características das sentenças judiciais envolvendo casos oftalmológicos no estado de São Paulo. O Tribunal de Justiça do Estado de São Paulo, parte do Poder Judiciário de São Paulo, é responsável pelo julgamento em grau de recurso, ou seja, das apelações às sentenças originárias da primeira instância. Neste trabalho não foram analisados processos em primeira instância, pois só recentemente estes passaram a ser disponibilizados online. O levantamento resultou num total de 55 acórdãos que preencheram os critérios de inclusão.

Observamos que, na maioria dos casos, os processos não envolviam queixas relacionadas com eventos de urgência e emergência, sendo que $91 \%$ do total relatou como causa principal a insatisfação com algum tipo de procedimento cirúrgico. Portanto, os casos cirúrgicos oftalmológicos eletivos lideram as causas de processos médicos, tal qual ocorre em outras áreas cirúrgicas da medicina ${ }^{2}$. Em levantamento prévio realizado pelo CREMESP, especialidades cirúrgicas como a Ginecologia e Urologia foram responsáveis pela maioria das causas de litígios, sendo a Oftalmologia a sétima colocada entre todas as especialidades médicas em número de denúncias no estado de São Paulo².

A responsabilidade civil médica é subjetiva, ou seja, é necessário que se prove ação culposa do profissional em caso de erro médico, e tem como pressuposto a existência de violação a um dever ${ }^{6}$. Além disso, em relação a resultados de tratamentos, descreve Aguiar ${ }^{6}$ :

[...] a obrigação é de meios quando o profissional assume prestar um serviço ao qual dedicará atenção, cuidado e diligência exigidos pelas circunstâncias, de acordo com o seu título, com os recursos de que dispõe e com o desenvolvimento atual da ciência, sem se comprometer com a obtenção de um certo resultado. O médico, normalmente, assume uma obrigação de meios.

Em especial no caso de cirurgias plásticas embelezadoras, o profissional médico se compromete com o resultado final, dessa forma a responsabilidade acaba sendo de fins e não de meios ${ }^{1}$.

A caracterização do erro médico deve se enquadrar em pelo menos uma de suas três atribuições: imperícia, imprudência e negligência. A imperícia se caracteriza pelo despreparo técnico do profissional; a imprudência se evidencia quando o médico age sem a devida cautela e de forma arriscada e, por fim, a negligência médica equivale a uma conduta omissiva, descuido, desinteresse ou passividade ${ }^{7}$. Todas as ações analisadas apresentavam acusação por erro médico, sendo citados negligência, imprudência e imperícia isoladamente ou em conjunto na seguinte frequência: imperícia citada 45 vezes, negligência 20 vezes e imprudência 11 vezes. Dessa forma, observamos que em grande parte dos litígios, os autores demostram contrariedade e dúvidas principalmente quanto à capacidade técnica dos profissionais que os assistiram. A análise dos litígios revelou que resultados insatisfatórios de procedimentos cirúrgicos levantam questionamentos quanto à capacidade do médico, mesmo nos casos em que não há comprovação de falha nas normas técnicas e quando o autor é orientado sobre os riscos inerentes ao procedimento. Isso leva à reflexão sobre a responsabilidade e a importância do esclarecimento correto e transparente no pré-operatório em relação aos riscos e as limitações dos procedimentos oftalmológicos, geralmente ligados a grandes expectativas por parte dos pacientes. Uma melhor orientação certamente poderia 
reduzir o número de processos, tanto pelo entendimento dos pacientes operados quanto pela não realização de procedimentos eletivos naqueles que não forem capazes de compreender sobre seus riscos. Um estudo prévio com pacientes não oftalmológicos mostrou que apenas $25 \%$ das orientações sobre riscos cirúrgicos explicados aos pacientes eram assimilados ${ }^{8}$, mostrando que seria importante repetir tais informações várias vezes.

Em relação aos estabelecimentos médicos, diferentemente do que ocorre com o médico, a responsabilidade é considerada objetiva. De acordo com o Código de Defesa do Consumidor em seu artigo 14: "o fornecedor de serviços responde, independentemente da existência de culpa, pela reparação de danos causados aos consumidores". Porém, os estabelecimentos só podem ser responsabilizados quanto ao fornecimento de equipamentos, estruturas e normas adequadas, mas não em relação aos médicos que neles atuam ${ }^{7}$. Quando estudamos o pólo de acusação dos acórdãos, vimos que em $34,5 \%$ dos casos tanto o médico quanto a instituição de assistência foram alvo, em $42 \%$ somente a instituição e em $23,5 \%$ somente o médico foi réu do processo. Isto mostra que os autores muitas vezes optam por apelar às Instituições onde foram assistidos, colocando-as como corresponsáveis e consequentemente reivindicando indenizações por danos causados.

Tomkins ${ }^{9}$, Ali $^{10}$ e Matthew ${ }^{11}$ em seus trabalhos mostraram resultados concordantes com os encontrados no presente estudo, em que as cirurgias de catarata lideraram o volume de procedimentos oftalmológicos e não é de se surpreender que liderem também o volume de processos médicos. $\mathrm{Na}$ análise não tivemos acesso aos dados médicos em si, portanto não pudemos avaliar minuciosamente as queixas médicas dos pacientes. Os acórdãos mencionam os motivos pelos quais o autor pede apelação, citam achados de perícias, mas não há dados suficientes para destrinchar cada processo. Por esse motivo, não foi possível obter dados como acuidade visual dos pacientes, indicações cirúrgicas, termos de consentimento, relatórios de atendimentos médicos, prontuários médicos, exames físico e complementar, fichas operatórias, dados clínicos, laudos médicos, etc.

A perícia médica tem importância fundamental em casos de erro médico, pois trata-se de matéria sobre a qual o magistrado não tem domínio, e seu julgamento poderá se basear nos resultados e conclusões da avaliação pericial. Apesar de não ter sido possível analisar os laudos e dados médicos na íntegra, obtivemos dados sobre as condenações e se estas foram baseadas nas perícias. $\mathrm{Na}$ maioria dos casos $(90,9 \%)$, o autor foi submetido à perícia médica, e a decisão do juiz baseou-se no laudo pericial em 86\% das ações. Dispõe o artigo 436 do Código de Processo Civil que: “O juiz não está adstrito ao laudo pericial, podendo formar a sua convicção com outros elementos ou fatos provados nos autos", ou seja, o juiz não é obrigado a aceitar as conclusões e resultados das análises dos peritos, sendo livre para deliberar conforme seu próprio entendimento. $\mathrm{Na}$ prática, observamos que, na maioria dos casos, o juiz considerou o laudo pericial em sua decisão. Não foi possível saber se as perícias foram realizadas por médicos especialistas em oftalmologia ou por médicos peritos generalistas, pois os acórdãos não disponibilizaram esse dado.

Por fim, analisamos e subdividimos em grupos as principais conclusões periciais, quando disponíveis. De modo geral, em 76,5\% dos casos a perícia descartou a presença de nexo causal, seja por não ter sido encontrado erro médico em cirurgia, pela presença de outras patologias oculares ou pela ausência de relação com o desfecho final relatado pelo autor. Somente em 1,8\% dos casos a perícia comprovou a presença de nexo causal. Paralelamente, quando observamos as alegações dos autores, somando os que afirmaram perda total e perda parcial da visão, chegamos a um total de $83,5 \%$ de descontentamento com a acuidade visual final após intervenção médica. Estes dados parecem indicar que, assim como já observado por outros autores ${ }^{12,13}$, os casos em sua maioria resultam de insatisfação com resultados e não por erro médico.

$\mathrm{O}$ volume de cirurgias de catarata realizadas em mutirões no Sistema Único de Saúde (SUS) em todo território nacional entre 1999 e 2005, segundo dados do Conselho Brasileiro de Oftalmologia, foi de 1.843.770. Este número nos ajuda a ter uma visão do quão espantosa é a quantidade de procedimentos realizados por ano. A relativa facilidade com que se realizam cirurgias de catarata e os avanços que proporcionaram rapidez, segurança e bons resultados, possibilitando a realização de dezenas e até centenas de cirurgias diariamente não deve ofuscar a importância do esclarecimento, das orientações, do acompanhamento e da assistência pré e pós operatória de cada paciente, pois, se por um lado o posicionamento dos pacientes vem multiplicando o número de litígios, por outro, é necessário que haja um esforço constante para preservação da ética na medicina, que deve andar lado a lado com os avanços terapêuticos.

\section{CONCLUSÃO}

Todas as ações analisadas apresentavam acusação por negligência, imprudência e imperícia de forma isolada ou sobrepondo duas ou mais alegações. Em $90,9 \%$, o autor foi submetido à perícia médica e, entre estes casos, a decisão judicial baseou-se no laudo pericial em $86 \%$ das vezes. Em relação à decisão judicial, $81,8 \%$ dos pedidos foram indeferidos em segunda instância, $9,1 \%$ deferidos e $9,1 \%$ obtiveram provimento parcial do pedido.

Os dados apresentados mostraram o papel 
fundamental da perícia médica nos processos por erro médico, expondo a sua importância nas decisões judiciais. A compreensão dos processos de erros médicos é um assunto delicado e muitas vezes incômodo, mas seja qual for a especialidade em pauta, presta-se também a contribuir com uma melhor assistência médica.

Yamauti K; Zerbini T. Ophthalmology in Court: evaluation of sentences according to The Justice Court of Sao Paulo Brazil. Saúde, Ética \& Justiça. 2014;19(2):78-85.

ABSTRACT: Ophthalmology is a medical specialty that involves clinical and surgical treatment for a broad spectrum of pathologies, and it is at risk of being subjected to legal proceedings of various kinds. These lawsuits against ophthalmologists and medical organizations range from complaints about prescription glasses to the results of complex surgical procedures. The aim of this study was to assess the lawsuits related to medical error in the ophthalmology field judged on appeal by the Justice Court of São Paulo, Brazil (TJ-SP) through an online data search of second instances of sentences available between 01/01/1997 and 09/30/2014, using the terms "ophthalmologist" and "medical error". The result was a total of 100 cases, 55 of which were included in the study of interest. All lawsuits had the charge of malpractice; $91 \%$, involving surgical procedures. In $61.8 \%$ of the judgments, the complainant alleged blindness and $23.6 \%$ aesthetic damage. In most cases, there was a forensic exam, and the judge's decision was based on the forensic exam report $86 \%$ of the time. Regarding the results of court decisions, $81.8 \%$ of applications were rejected on appeal, $9.1 \%$ were granted and $9.1 \%$ were granted partially. The data presented showed, among other findings, the fundamental role of the medical forensic exam in malpractice suits, indicating its importance in judicial decisions.

KEYWORDS: Ophthalmology; Medical errors, negligence, jurisprudence.

\section{REFERÊNCIAS}

1. Brasil. Superior Tribunal de Justiça (STJ). Processos por erro médico no STJ aumentaram $200 \%$ em seis anos [Internet]. Brasília, DF; 2008 [2008 nov 09; acesso em 2014 out 09]. Disponível em: http://ftp.stj.jus.br/portal_stj/ publicacao/engine.wsp?tmp. $\cdot$ rea $=398 \&$ tmp.texto $=89920$

2. Conselho Regional de Medicina do Estado de São Paulo (CREMESP). Denúncias e processos relacionados ao exercício profissional da medicina no Estado de São Paulo no período de 2000 a 2006. São Paulo, SP; 2007 [2007 out 09; acesso em 2014 nov 01]. Disponível em: http://www. cremesp.org.br/library/modulos/sala_imprensa/arquivos/ denuncias_cremesp.pdf

3. Caprara A, Rodrigues J. A relação assimétrica médicopaciente: repensando o vínculo terapêutico. Cien Saude Colet. 2004;9(1):139-46. DOI: http://dx.doi.org/10.1590/ S1413-8123004000100014

4. Santos W, Solari HP, Ventura MP. Processos judiciais em oftalmologia: análise de possíveis fatores desencadeantes. Arq. Bras. Oftalmol. 2010;73(6):501-4. DOI: http://dx.doi. org/10.1590/S0004-27492010000600006

5. Leitch RJ. Is medicolegal work a duty? Br J Ophthalmol. 2003;87(4):383. DOI: http://dx.doi.org/10.1136/ bjo.87.4.383

6. Aguiar Junior RR. Responsabilidade civil do médico. In: Teixeira SF. Direito e medicina: aspectos jurídicos da medicina. Belo Horizonte: Del Rey; 2000. p.133-80.
7. Almeida BCC. Responsabilidade civil médica e o código de defesa do consumidor. Revista Internacional de Direito e Cidadania. 2011;10:41-53.

8. Godwin Y. Do they listen? A review of information retained by patients following consent for reduction mammoplasty. Br J Plast Surg. 2000;53(2):121-5. DOI: http://dx.doi. org/10.1054/bjps.1999.3220

9. Tomkins C. Over 120 years of defending ophthalmologists. Br J Ophthalmol. 2006;90(9):1084-85. DOI: http://dx.doi. org/10.1136/bjo.2006.097311

10. Ali N. A decade of clinical negligence in ophthalmology. BMC Ophthalmol. 2007;7:20. DOI: http://dx.doi. org/10.1186/1471-2415-7-20

11. Mathew RG, Ferguson V, Hingorani M. Clinical Negligence in Ophthalmology: Fifteen Years of National Health Service Litigation Authority Data. Ophthalmology. 2013;120(4):859-64. DOI: http://dx.doi.org/10.1016/j. optha.2012.01.009

12. Kraushar MF, Robb JH. Ophthalmic malpractice lawsuits with large monetary awards. Arch Ophthalmol. 1996;114(3):333-7. DOI: http://dx.doi.org/10.1001/ archopht.1996.01100130329019

13. Ali N, Little BC. Causes of cataract surgery malpractice claims in England 1995-2008. Br J Ophthalmol. 2011;95(4):490-2. DOI: http://dx.doi.org/10.1136/ bjo.2010.182774. 